\section{A educação dos profisisonais de saúde na América Latina: teoria e prática de um movimento de mudança}

ALMEIDA, M., FEUERWERKER, L., LLANOS, M. (Orgs.). São Paulo: Hucitec; Buenos Aires: Lugar Editorial; Londrina: Ed. UEL, 1999. $2 v$.

A formação e o trabalho dos profissionais de saúde na América Latina vêm sendo decisivamente impactados pela reorganização dos sistemas de saúde, pelas pressões para a reforma da Universidade $e$ pelo processo de reforma e descentralização político-administrativa do Estado. Às forças comuns que respondem por um conjunto de políticas públicas "globalizadas" se contrapõe uma diversidade de respostas nos diferentes países, que se traduzem em múltiplas alternativas de conformação de modelos de organização de cuidados à saúde, de regulação de mercados de trabalho e de exercício profissional, de revisão da relevância social da Universidade e de seus processos de formação profissional, e de redefinição de atores em novas esferas de decisão em sistemas mais descentralizados de gestão com graus diversos de controle social.

Assim abordadas, parecem claras para muitos de nós as relações entre o contexto acima descrito $e$ as práticas da formação profissional em saúde. Faz sentido imaginar que todas essas condições se traduzam concretamente, em maior ou menor grau, nas práticas cotidianas das pessoas em seus espaços de trabalho - quer sejam os ambulatórios e hospitais, as faculdades $e$ escolas das ciências da saúde - e nas relações entre os usuários dos serviços, alunos, professores e profissionais da saúde.

Entretanto, ao pensar nas escolas existentes em nossos países, observamos que o que parecia tão claro se obscurece. A maior parte dos processos de formação, por estar fundamentada preponderantemente em um modelo disciplinar centrado na racionalidade biomédica, remete alunos e professores uma redução drástica dos processos de saúde-doença à sua dimensão biológica, dos sujeitos/pacientes à sua doença, da doença dos sujeitos ao seu substrato anátomopatológico, e do cuidado ao protocolo de medidas terapêuticas aplicáveis à nosologia em questão. Esta redução subtrai, aparentemente, da formação profissional todas as outras dimensões que permitem configurar o exercício profissional como uma prática socialmente construída, que comporta visões de mundo, intencionalidades, contradições.

Para asssim fazê-lo, a organização curricular assenta-se em sólida base de disciplinas biomédicas, cujo domínio teórico é a condição para o início da formação profissional, postergada para a segunda metade do curso. De forma pretensamente neutra, defende-se que a prática no ambiente hospitalar permite a exposição aos melhores recursos de que a ciência dispõe para oferecer às pessoas, aí reduzidas, muitas vezes, a objetos de aprendizagem de alunos que nelas não reconhecem seus futuros pacientes. Em outras palavras, no cotidiano das escolas que formam profissionais da saúde é como se prevalecesse um "outro" contexto, construído e reproduzido nas enfermarias e nas salas de aula, no qual não cabem muitas das contradições do mundo de fora, do "extra-muros".

As iniciativas de reforma comprometidas com a relevância social da escola e dos processos de formação no campo da saúde 
têm historicamente procurado articular esses dois contextos aparentemente desconectados - universidade e serviços buscando ligar os espaços de formação aos diferentes cenários da vida real e de prestação de cuidados à saúde. Essa foi, por exemplo, a perspectiva central do movimento de integração docente-assistencial (IDA) que prevaleceu nos anos oitenta como estratégia relevante de mudança.

Considerando a experiência acumulada nos últimos quarenta anos, particularmente no campo da educação médica, $e$ reconhecendo a inadequação dos modelos de formação para enfrentar os desafios atuais da atenção à saúde, é formulado, no início dos anos noventa, por iniciativa da Fundação Kellogg, o Programa UNI (Uma Nova Iniciativa na Educação dos Profissionais de Saúde - União com a Comunidade). Sua proposição central é que a relação de parceria entre a universidade, os serviços locais de saúde e a comunidade seja a base sobre a qual devem estar fundados os processos de transformação da educação dos profissionais e dos sistemas de saúde. Até então, esses atores estabeleciam entre si relações bilaterais, expressas pela Integração Docente-Assistencial (Universidade-Serviços), pela Extensão Universitária (UniversidadeComunidade) e pela Atenção Primária à Saúde (Serviços-Comunidade). O UNI propõe, em contraposição, articular esses três atores num sistema mais complexo e orientado para a inovação das práticas de saúde e da formação profissional.

$\mathrm{Na}$ década de noventa, com investimentos da Fundação Kellogg da ordem de cincoenta milhões de dólares, foram desenvolvidos 23 projetos em 11 países da América Latina, envolvendo 103 cursos de graduação de 23 universidades, 23 secretarias municipais ou coordenações regionais de saúde, serviços de diferentes níveis de complexidade e mais de 600 organizações comunitárias. Além de financiar a elaboração e o desenvolvimento dos projetos, o apoio da Fundação incluiu os recursos necessários para um cuidadoso processo de formação de lideranças, bem como de acompanhamento e avaliação das experiências.

São essas experiências, olhadas sob diferentes ângulos e perspectivas, que compõem o livro $A$ Educação dos Profissionais na América Latina - Teoria e Prática de um Movimento de Mudança, editado em dois tomos, instigantes tanto por seus conteúdos específicos como pela complementariedade que oferecem.

O primeiro, Um Olhar Analítico, traz a contribuição de autores reconhecidamente comprometidos com a construção do próprio ideário UNI e de consultores externos aos projetos, que têm como objeto de investigação e prática elementos essenciais $e$ constituintes dos processos UNI2.

Ao analisarem o percurso histórico da saúde e da educação, os autoresformuladores permitem ao leitor compreeender as bases da elaboração do UNI enquanto constructo que representa a reelaboração das experiências pregressas $e$ a projeção de um novo referencial de ação.

Suas proposições expressam um conjunto de estratégias - ajustadas às demandas contemporâneas da formação e provisão de cuidados à saúde - que reafirmam os compromissos de cidadania, de eqüidade e de justiça social, e conferem ao programa relevância crucial no contexto latinoamericano.

A experiência acumulada nos oito anos de desenvolvimento do programa permite a esses autores-formuladores revisitar o

\footnotetext{
${ }^{2}$ Achamos importante, para efeito desta resenha, diferenciar a natureza das contribuições desses dois tipos de colaboradores. Os autores-formuladores, por chamar assim, são aqui entendidos como aqueles comprometidos com a formulação do ideário e/ou a implementação dos programas institucionais da Kellogg. Os consultores externos, por sua vez, não têm vinculação com os projetos, o que lhes permite um olhar mais distanciado e, por sua expertise, uma contribuição de natureza mais teórica. Essa distinção pretende, tão somente, realçar a especificidade e a complementariedade desses dois tipos de contribuições.
} 
ideário e demonstrar explicitamente uma de suas virtudes, aquela que assume que o processo é de construção e de des-construção permanente. Nesse caminho, são abordados os avanços inquestionáveis alcançados, dentre os quais destacamos: a conformação dos projetos enquanto espaços de construção democrática, contando com a participação de atores até então distantes, na maioria dos casos, dos cenários de negociação criados; $e$ a constituição de sujeitos orientados por projetos coletivos que resgatam valores como a solidariedade e a responsabilidade compartilhada.

A reconstrução da proposta pelos autoresformuladores parte do reconhecimento do limitado grau de estruturação teóricoconceitual inicial e da análise de suas implicações para o desenvolvimento dos projetos. A diversidade de iniciativas, estimulada e preservada como riqueza $e$ força do programa, requeria, por sua vez, compreensão e análise da heterogeneidade dos cenários locais e de seus problemas para a elaboração de estratégias efetivas por parte do Programa, cujo timing, retrospectivamente, parece não ter sido ajustado às necessidades. Como formuladores, reavaliam os tempos e espaços políticos para a construção da sustentabilidade e da institucionalização dos propósitos UNI e dos resultados concretos obtidos.

Os consultores externos, com base em suas experiências em diferentes projetos $e$ em suas respectivas áreas de expertise, contribuem com uma reflexão sobre conceitos-chave da proposta UNI. Iluminam, desta forma, muitas observações dos protagonistas dos diferentes projetos contidas no Tomo II e reafirmam a densidade teórica de muitas das conclusões apresentadas pelos autores-formuladores.

Entre os conceitos criticados pelos consultores destaca-se o de parceria, categoria central na construção da proposta UNI. Apresentada no plano formal como substantiva, horizontal e igualitária entre os componentes (academia, serviços e comunidade), a parceria aparece na proposta, entretanto, desprovida de seu ingrediente essencial, aquele que define, de fato, o rumo e o sentido da negociação: o poder. Ao negligenciá-lo, a proposta, na verdade, está assumindo como homogêneos cada um desses componentes, $e$ subestimando as desigualdades de poderes $e$ saberes entre eles $e$ as contradições delas decorrentes. Em conseqüência, tende a subestimar as possibilidades de reprodução da hegemonia da Universidade, pretensamente anuladas pela paridade formal da representação de todos os componentes nos espaços de negociação. A realidade do desenvolvimento dos projetos, no entanto, mostrou rapidamente os limites dessa concepção, e as descrições das experiências dos projetos, contidas no segundo volume, revelam as disputas ocorridas tanto no interior da academia, dos serviços e da comunidade, como nos espaços de negociação entre eles.

É interessante chamar a atenção, ademais, para o tratamento que é dado a outras questões relevantes para a análise de experiências comprometidas com as transformações das práticas em saúde. Entre elas queremos destacar: o conceito de modelo assistencial que orienta a formulação de estratégias de articulação com os serviços de saúde, particularmente relevante para o contexto brasileiro de construção do SUS e de municipalização; as concepções de trabalho com a comunidade sob as perspectivas da gestão e da parceria, principalmente por sua importância na discussão do controle social e das práticas de promoção à saúde; e os desafios, no plano educacional propriamente dito, da formação $e$ do desenvolvimento de recursos humanos em saúde. Salientamos, ainda, o espaço privilegiado que ocupa a abordagem da avaliação enquanto ferramenta e como processo, e a ênfase dada ao detalhamento metodológico, histórico e crítico da avaliação do cluster UNI. Por fim, o enfoque integrado 
das mudanças organizacionais que tiveram lugar na academia, nos serviços de saúde e nas entidades comunitárias exemplifica com clareza como pode ser fecunda a análise dos processos de transformação das práticas em saúde quando assentados na interdisciplinariedade.

\section{O segundo tomo, As Vozes dos}

Protagonistas, apresenta as experiências dos diferentes projetos desenvolvidos na América Latina. Está organizado de forma a destacar, em sua primeira parte, as experiências que têm como objeto de reflexão as próprias estratégias de desenvolvimento dos projetos. A parte seguinte aglutina artigos que relatam e analisam diferentes experiências na construção das parcerias, abordando a especificidade desse processo em relação tanto às inovações na formação profissional, nas práticas de saúde, e na gestão dos serviços, quanto à criação de novos espaços de participação social em saúde.

Analisado sob um outro ângulo, este tomo permite, ademais, uma fértil reflexão sobre o plano político das transformações promovidas pelos projetos UNI, no sentido de suas possibilidades e limites para influenciar as políticas públicas de educação e saúde. Ganha destaque, nesta abordagem, a discussão de redes como espaços de conformação de um novo ator social, representado pela força dos projetos UNI. No Brasil, a participação da rede UNIDA no processo de definição das diretrizes curriculares promovido pelo MEC exemplifica o potencial desta articulação.

A maior riqueza desse tomo reside na polifonia e na diversidade de abordagens que a singularidade de cada projeto comporta, aí considerados os contextos específicos de seu desenvolvimento. Seria de todo impossível $e$ fugiria ao escopo desta breve resenha analisar as contribuições dos diversos colaboradores. Chama a atenção, entretanto, no conjunto de artigos apresentados, o compromisso com a inovação $e$ a construção de parcerias e de novas práticas nos âmbitos dos serviços, da universidade e da comunidade, traduzido não apenas nos relatos sobre o realizado mas, sobretudo, nos desafios e nas novas perguntas que surgiram no decorrer do processo. As palavras de um dos autores "...ao começar era muito difícil entender a natureza dos processos que pretendíamos modificar e com isso reconhecer a dimensão da tarefa" (p.55) anima-nos a destacar a enorme importância que a ruptura das certezas $e$ o reconhecimento do desconhecido e da natureza dinâmica das transformações têm para a análise dessas experiências sob a perspectiva de seus sujeitos. Ao fazê-lo, os atores que trabalham por mudanças na formação profissional no campo da saúde preponderantemente biologicista, mecanicista, ahistórica - podem perceber como ela própria, ao eliminar a dimensão social de sua natureza, obstaculiza a sua compreensão e, ao mesmo tempo, o potencial que cada sujeito tem de transformá-la.

Entendidas nesta dimensão de reconstrução das práticas dos sujeitos, as experiências relatadas expressam a possibilidade de construir caminhos num cenário político de fragmentação de interesses e em que se busca fazer prevalecer a idéia de que não há alternativas senão aquelas já definidas e desenhadas por macropolíticas sobre as quais nada mais podemos fazer. Expressam, sobretudo, a força das transformações possíveis nos nossos espaços cotidianos de trabalho, nos ambulatórios, nas enfermarias, nas faculdades, nas organizações da sociedade civil. Traduzem laços solidários e dão sentido à riqueza das conexões, ao poder de novas redes que mobilizam intencionalidades $e$ vínculos.

Eliana Claudia de Otero Ribeiro Professora do Laboratório de Currículo e Ensino do Núcleo de Tecnologia Educacional para a Saúde (NUTES) da Universidade Federal do Rio de Janeiro. <eclaudia@unisys.com.br> 